\title{
The impact of hospital-based and community based models of cerebral palsy rehabilitation: a quasi-experimental study
}

\author{
Jermaine $\mathrm{M} \mathrm{Dambi}^{1^{*}}$ and Jennifer Jelsma
}

\begin{abstract}
Background: Cerebral palsy requires appropriate on-going rehabilitation intervention which should effectively meet the needs of both children and parents/care-givers. The provision of effective support is a challenge, particularly in resource constrained settings. A quasi-experimental pragmatic research design was used to compare the impact of two models of rehabilitation service delivery currently offered in Harare, Zimbabwe, an outreach-based programme and the other institution-based.
\end{abstract}

Method: Questionnaires were distributed to 46 caregivers of children with cerebral palsy at baseline and after three months. Twenty children received rehabilitation services in a community setting and 26 received services as outpatients at a central hospital. The Gross Motor Function Measurement was used to assess functional change. The burden of care was measured using the Caregiver Strain Index, satisfaction with physiotherapy was assessed using the modified Medrisk satisfaction with physiotherapy services questionnaire and compliance was measured as the proportion met of the scheduled appointments.

Results: Children receiving outreach-based treatment were significantly older than children in the institution-based group. Regression analysis revealed that, once age and level of severity were controlled for, children in the outreach-based treatment group improved their motor function $6 \%$ more than children receiving institution-based services.

There were no differences detected between the groups with regard to caregiver well-being and $51 \%$ of the caregivers reported signs consistent with clinical distress/depression. Most caregivers (83\%) expressed that they were overwhelmed by the caregiving role and this increased with the chronicity of care. The financial burden of caregiver was predictive of caregiver strain.

Caregivers in the outreach-based group reported greater satisfaction with services and were more compliant $(p<.001)$ as compared to recipients of institution-based services.

Conclusion: Long term caregiving leads to strain in caregivers and there is a need to design interventions to alleviate the burden. The study was a pragmatic, quasi-experimental study thus causality cannot be inferred. However findings from this study suggest that the provision of care within a community setting as part of a well-structured outreach programme may be preferable method of service delivery within a resource-constrained context. It was associated with a greater improvement in functioning, greater satisfaction with services and better compliance.

Keywords: Cerebral palsy, Community based rehabilitation, Institution based intervention, Rehabilitation, Zimbabwe

\footnotetext{
*Correspondence: jermainedambi@gmail.com

${ }^{1}$ Research Fellow at University of Cape Town, Lecturer Department of Rehabilitation, College of Health Sciences, University of Zimbabwe, PO Box AV 178, Avondale, Harare, Zimbabwe

Full list of author information is available at the end of the article
} 


\section{Background}

Cerebral palsy $(\mathrm{CP})$ is the most common paediatric neurological condition [1] and the principal cause of disability in children globally [2]. It is defined as "a group of disorders of the development of movement and posture, causing activity limitation, that are attributed to nonprogressive disturbances that occurred in the developing fetal or infant brain. The motor disorders of cerebral palsy are often accompanied by disturbances of sensation, cognition, communication, perception, and/or behaviour, and/or by a seizure disorder" [3]. CP is a universal problem [2] with a global incidence of 2 to 3 cases per 1000 births [4]. The exact prevalence in Zimbabwe is unknown: however, from extrapolated data, the incidence is similar and estimated at 1.55/1000 in rural areas and 3.3/1000 in urban areas [5].

Children with CP face multiple bio-psychosocial challenges $[6,7]$. This coupled to the fact that $\mathrm{CP}$ is a lifetime condition $[2,3,8]$, may result in a considerable burden on caregivers of children with severe impairments, affecting their health and health related quality of life $[9,10]$. Rehabilitation treatment is an essential component $[1,11]$ of the multi-disciplinary approach required to address the problems of children with CP and their families $[8,12]$. Researchers have not yet identified the most effective method of service delivery in terms of optimising the child's potential and providing support to the caregiver, especially in low-income countries such as Zimbabwe. Issues such as accessibility and acceptability of services, compliance with training and efficacy of the intervention need to be considered when implementing any model of service delivery.

Different models of rehabilitation service delivery have been proposed in an attempt to provide affordable and appropriate support to people living with disabilities and these can be broadly classified as either institution-based (IB) or community based rehabilitation (CBR)/outreachbased (OR) approaches $[13,14]$. The roots of CBR can be traced back to the Declaration of Alma-Atta which led to the adoption of the global primary health care strategy by the World Health Organization (WHO). The aim of CBR was to provide primary health care and rehabilitation services to people with disabilities within their communities [15]. CBR has been in existence for more than 3 decades [15-18] yet little is known about its efficacy, effectiveness, relevance, appropriateness and sustainability as a service delivery model and public health strategy [19-21].

Zimbabwe utilizes a hybrid model of provision of rehabilitation services that is a blend of hospital-based and community-based approaches which are provided at district, provincial and central hospitals [22]. Unfortunately, a decade of socio-economic meltdown has resulted in deterioration of the health care delivery system [23]. At present, organization of rehabilitation services varies from institution to institution and is mainly governed by resource availability. Most institutions are now offering hospital-based services only. For instance, out of the six state central hospitals in Zimbabwe, only Harare Central Hospital $(\mathrm{HCH})$ is at present running a consistent outreach program through its Children Rehabilitation Unit (CRU) [22]. The CRU is a specialized paediatric rehabilitation centre, which, for more than twenty years, has run a peri-urban, community-based outreach programme based on the WHO CBR model. Children and their care-givers (mostly mothers) gather in groups twice a month in community centres. Children receive some individual treatment from therapists and/or rehabilitation technicians (who have undergone two years of training). In addition, there are group activities and education sessions. In contrast, children in another high-density area of Harare, which is serviced by a different hospital, receive regular physiotherapy within an institutional out-patient setting. As the outreach programme relies on a certain amount of donor funding, it is somewhat more expensive to run [22].

There was a clear need to compare the two models of service delivery, not only to inform the on-going re-structuring of rehabilitation services in Zimbabwe [23], but to provide empirical evidence of the relative impact of CBR/outreach services as compared to institutionallybased rehabilitation [11].

The objectives of the study were therefore to compare the impact of the outreach (OR) and the institutionally based (IB) programs in terms of their impact on the children's functioning, the strain on their caregivers, compliance with scheduled appointments and the overall satisfaction with the services received. It was anticipated that there would be little difference in the functional change between the two groups. The greater group interaction and support were expected to result in a greater decrease in the strain of the care-givers attending the outreach group. The satisfaction with services was expected to be greater in the outreach group as the service was brought to them and they did not need to travel far to get support for their children.

\section{Methods}

A quasi-experimental design was used as it was a pragmatic trial and it was not possible to randomly assign children to one group or the other. The geographical location determines a child's program allocation as the two areas are some distance apart, children and caregivers were thus obliged to attend one or other programme depending on their place of residence. A sample of convenience was drawn from the children treated under the OR program and IB CP clinics who attended the clinics during the first four weeks of the study. 
The children had to have received a diagnosis of CP according to their patient notes. They were to be between 0.5 to 12 years of age as the Gross Motor Function Measure (GMFM) has good content and face validity for children in the age range 0.5 to 13 years [24] and the discharge age for the CRU Outreach program is 12 years. No participant was recruited if they were scheduled for surgery or if they had any other significant medical and nutritional problems or other clinical factors that might have biased the rehabilitation program $[25,26]$. Children who had comorbid neurological conditions e.g. Spinal Bifida or who were receiving other forms of therapeutic interventions such as private physiotherapy were similarly excluded.

The burden of care as measured by the Caregiver Strain Index (CSI) [27] was one of the major variables under scrutiny. Assuming mean CSI scores of 7 and 9 $(\mathrm{SD}=2)$ for both groups [28] at the conclusion of the study period, the expected minimal number of cases per group was 16 (alpha $=.05$, power $=95 \%)$. Oversampling was done to counteract effects of attrition due to e.g. sickness and non-compliance.

\section{Instrumentation}

The Gross Motor Function Measure -66 item version (GMFM-66) is a condition specific and widely used, standardized and validated ordinal scale which measures changes in motor function in children with CP $[24,29,30]$. Functional prognosis is dependent on level of severity and this we measured using the Gross Motor Function Classification System (GMFCS) which is a valid and reliable tool [24,31]. This classifies severity on a 5 -level ordinal scale, with children in level one being least affected and level five being more severely affected and functionally dependent [31]. The Caregiver Strain Index [32] and Medrisk Instrument for Measuring Patient Satisfaction with Physical Therapy Care (MRPS), [33] have been reported to be valid and reliable tools in measuring the burden of care and satisfaction with services respectively $[27,33]$. The tools were translated into the native language, Shona, using a backwardforward approach. The tools were then validated on a group of caregivers, $n=20$ of children with CP receiving outpatient services at CRU who were not part of the main study. The caregivers completed the questionnaires and were requested to give comments on the appropriateness, validity and clarity of the tools. After feedback, the tools were re-administered after a week in order to assess the internal consistency (Cronbach's alpha $=.78)$, validity and reliability $(\mathrm{r}=.82)$ of the tools, all of which were found to be acceptable.

\section{Intervention}

The children and parents (mostly mothers) in the OR arm gathered in groups twice a month in community centres. In the IB arm, the frequency of appointments was variable and was dependent on the discretion of the treating therapists. In both arms, children received some individual face to face treatment from therapists. In addition, the OR arm received group activities, where caregivers were requested to demonstrate home exercise programs to other caregivers as well as sharing the challenges and achievements of caregiving. Additionally, the OR arm received educational sessions on the aetiology, management of $\mathrm{CP}$ and ways of coping with the associated burden of care. They were provided with light refreshment after therapy sessions and were given the option to participate in caregiver support group activities such as joint income generation projects. The OR programme receives donor funding and employs more rehabilitation professionals which improves the therapist/child ratio. In addition, allowances paid to professionals for every outreach outing makes it more expensive to run [22].

\section{Procedure}

A pilot study was done to determine the intra-rater reliability of the GMFCS and GMFM-66 scoring as well as refining data collection procedures (see above). Caregivers were then recruited by the research team over four consecutive weeks. Caregivers were approached as they were awaiting services or after their children were treated. Once informed consent had been obtained, CSI questionnaires were distributed to caregivers which were self-administered. The principal researcher then documented the motor function scores of children with CP using the GMFM-66 and the GMFCS. It would have been difficult to transport participants to a neutral venue so all assessments were done at usual treatment settings and the usual treatment days to avoid inconveniencing the caregivers. Consequently blinding to group membership was not possible. The compliance with scheduled appointments was captured throughout the study. Twelve weeks later, the same procedure was followed in scoring the CSI, GMFM-66 scores and additionally the modified MRPS questionnaire was applied. Both groups were provided with snacks and drinks after data collection procedures.

\section{Ethical considerations}

Ethical approval was granted by the University of Cape Town (ref 109/2012) and the Medical Research Council of Zimbabwe (MRCZ/B/333). Consent was sought from caregivers, rehabilitation professionals and verbal assent was requested from children who could communicate $(n=5)$. Fifteen caregivers refused consent. Caregivers were assigned identity numbers to preserve confidentiality and only the principal researcher had access to the collected raw data which was kept in a safe locker. Both groups of participants were treated equally to achieve social justice. 


\section{Data analysis}

Statistical analysis was performed using STATISTICA version 10. We used an alpha level of 0.05 for all statistical tests. Analysis was per protocol. As most of the data were non-parametric, the Mann-Whitney U, chi-squared and Fishers' Exact tests were used to compare results between the two groups in terms of the difference in demographics, MRPS and CSI. The scores on the GMFM66 were transformed into interval data using the Gross Motor Ability Estimator (GMAE-2) Scoring Software for the GMFM [34] which is a software package for scoring the Gross Motor Function Measure (GMFM) based on item response theory. A one way ANOVA was used to compute differences in GMFM-66 and CSI scores at different times.

As age was significantly different between the two groups and there were more severely affected children in the community based treatment group, regression analysis was done to establish which factors predicted the amount of change in the GMFM Score. Dummy variables were created for the categorical variable of the group and the ordinal variable of GMFCS was dichotomised into levels mild/moderate (I, II and III) and severe (IV and V). Residual analysis was performed and children who had residual scores of more than 2.5 SD from the mean were excluded.

\section{Results}

\section{Demographic and medical characteristics}

A total of 107 potential participants were approached for recruitment into the study, of these, 42 were from OR and 65 from IB. As can be seen in Figure 1, 32 did not meet the inclusion criteria or declined participation (15). A further four in the OR group and 11 in the IB were lost to follow-up for different reasons. Ultimately 20 in the OR and 26 children in the IB groups completed the study.

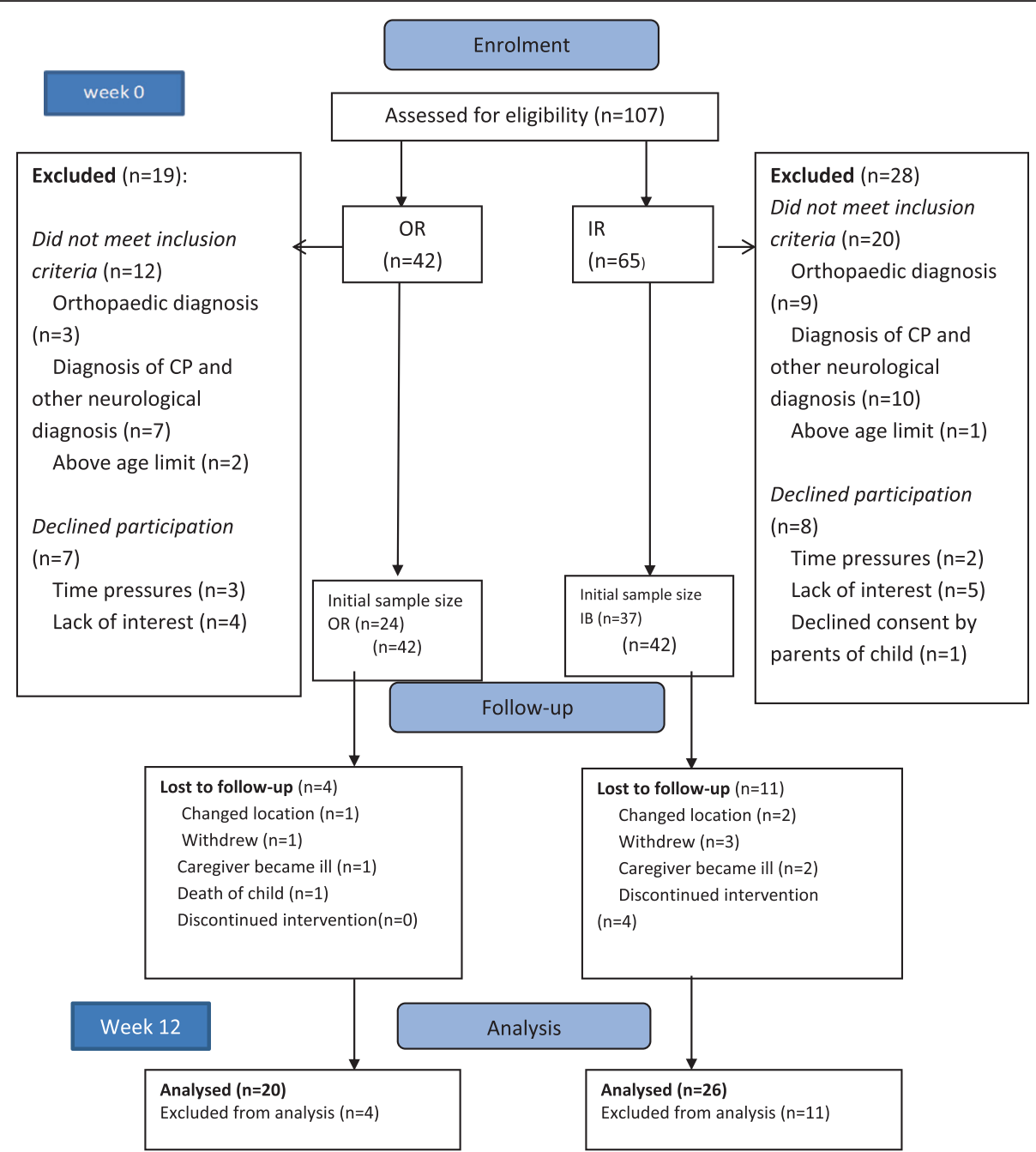

Figure 1 Flow chart of the study. 107 potential participants were approached, of which 28 did not meet the inclusion criterion. Of these, 15 were lost to follow up given a final sample size of 46 for data analysis. 
Demographic information on the 46 dyads of caregiver and child with $\mathrm{CP}$ who participated are presented in Table 1. Children receiving IB treatment were significantly younger than those in the OR group, (12 as opposed to 44 months). However, the two groups were comparable in terms of the socio-demographics of both children and caregivers at baseline. In the IB group 38\% of the children were in the most severe levels of the GMFCS, compared to 50\% in the OR group, however the proportions in each level were not significantly associated with group.

\section{Treatment sessions and compliance}

The therapist hour's ratio was calculated by dividing the product of number of therapists and total number hours of therapy provided by total number of children treated over the study period. As can be seen in Table 2, they were no statistically significant differences in terms of the organization of treatment sessions, $\chi^{2}=0.711, \mathrm{df}=1$, $\mathrm{p}=0.399$ and children in the OR group received a significantly higher amount of therapy time, $t(43)=3.19$, $\mathrm{p}=0.003$.

Caregivers in the OR group were expected to attend every two weeks and in the IB group, caregivers were given a variable number of appointments; this is illustrated in Table 3.

The percentage compliance was calculated by dividing the number of attendances by the maximum number of attendances possible. The mean percentage compliance was significantly greater in the OR group: $93.3 \%$ (median $=100$, range: $67-100$ ) for the OR group and $72.8 \%$ (median $=72.5$, range: $33-100)$ for the IB group, $(\mathrm{Z}=-3.56, \mathrm{p}<.001)$.

Table 1 Study population demographic characteristics, N= 46

\begin{tabular}{|c|c|c|c|c|c|c|}
\hline & & OR $(n=20)$ & IB $(n=26)$ & Total & Statistic & $\mathrm{p}$-value \\
\hline & & $\mathbf{n}$ & $\mathbf{n}$ & n (\%) & & \\
\hline \multirow[t]{2}{*}{ Gender } & Males & 11 & 14 & $25(54)$ & $x^{2}=0.049$ & 0.825 \\
\hline & Females & 9 & 12 & $21(46)$ & $\mathrm{df}=1^{*}$ & \\
\hline Mean age of children in months (SD) & & $44(49)$ & $12(7)$ & $26(36)$ & $U=170.0, Z=-1.928$ & 0.047 \\
\hline \multirow[t]{5}{*}{ GMFCS Level } & 1 & 5 & 8 & $13(28)$ & $U=0.790$ & 0.448 \\
\hline & $\|$ & 3 & 4 & $7(15)$ & $Z=0.429$ & \\
\hline & III & 2 & 4 & $6(13)$ & & \\
\hline & IV & 2 & 2 & $4(9)$ & & \\
\hline & V & 8 & 8 & $16(35)$ & & \\
\hline \multirow[t]{5}{*}{ CP type } & Spastic & 16 & 21 & $37(80)$ & $x^{2}=0.0$ & 0.948 \\
\hline & & & & & $d f=3$ & \\
\hline & Athetoid/dyskinetic & 3 & 2 & $5(11)$ & & \\
\hline & Ataxic & 1 & 1 & $2(4)$ & & \\
\hline & Mixed & 0 & 2 & $2(4)$ & & \\
\hline Mean caregiver age $(S D)$ in years & & $33(12)$ & $28(5)$ & $30.4(9.2)$ & $U=192.00, Z=1.496$ & 0.134 \\
\hline \multirow[t]{4}{*}{ Relationship to child } & Mother & 16 & 22 & $38(83)$ & $x^{2}=.710$ & 0.701 \\
\hline & & & & & $\mathrm{df}=2$ & \\
\hline & Grandmother & 2 & 3 & $5(11)$ & & \\
\hline & Sibling & 2 & 1 & $3(7)$ & & \\
\hline \multirow[t]{2}{*}{ Caregiver } & Primary & 2 & 2 & $4(9)$ & $x^{2}=4.268$ & 0.371 \\
\hline & & & & & $d f=3$ & \\
\hline \multirow[t]{3}{*}{ Educational level } & Secondary & 13 & 17 & $30(65)$ & & \\
\hline & Tertiary & 4 & 5 & $9(20)$ & & \\
\hline & None & 1 & 2 & $3(7)$ & & \\
\hline \multirow[t]{2}{*}{ Caregiver } & Unemployed & 12 & 16 & $28(61)$ & $x^{2}=0.802$ & 0.67 \\
\hline & & & & & $d f=2$ & \\
\hline \multirow[t]{2}{*}{ Employment status } & Informally employed & 7 & 7 & $14(30)$ & & \\
\hline & Formally employed & 1 & 3 & $4(9)$ & & \\
\hline
\end{tabular}

*- With Yates correction of continuity. 
Table 2 Treatment sessions details for the study duration

\begin{tabular}{|c|c|c|c|c|c|}
\hline & & OR & IB & Statistic & p-value \\
\hline \multirow[t]{3}{*}{ Type of treatment rendered } & Individual therapy sessions & 3 & 3 & $x^{2}=0.711$ & 0.399 \\
\hline & & & & $d f=1^{*}$ & \\
\hline & Health promotional talks & 6 & 3 & & \\
\hline \multirow[t]{3}{*}{ Therapist hours ratio } & Mean (SD) & $0.29(.07)$ & $0.21(.10)$ & $t(43)=3.19$ & 0.003 \\
\hline & Median & 0.30 & 0.37 & & \\
\hline & Range & $0.20-0.40$ & $0.27-0.54$ & & \\
\hline
\end{tabular}

*-With Yates correction of continuity.

\section{Impact on function}

The GMFM-66 scores over time (Table 4) were compared and whereas there were no between group differences detected, the improvement over time for both groups combined was significant.

The regression model (Table 5) with the change in GMFM-66 scores as dependent variable accounted for about a quarter of the variance (adjusted $\mathrm{R}^{2}=.27$ ) after residual analysis resulted in the scores of two children being removed. The results indicate that, once age and category were controlled for, children in the OR group improved 2.49 points more on the GMFM-66 than children receiving IB services. This equates to approximately a $6 \%$ difference in improvement $(2.49 / 41.5$ at baseline). Children who were less severely disabled showed 1.96 points more improvement and for each month of age, older children showed .02 less improvement

\section{Impact on caregivers}

The majority of both groups reported an impact on inconvenience, physical strain, confining, family adjustments; personal plans and work adjustments (Table 6). The greatest number reported problems with financial strain and feeling overwhelmed.

Further, the caregivers experienced a high burden of care (Table 7) and 50\% $(n=23)$ of the caregivers had scores greater than or equal to seven which is the cut-off point for clinical distress/depression [32].

The sign test indicated that there were no changes in CSI score over the course of the study $(\mathrm{p}=1.0)$. There were also no differences in the median scores between

Table 3 Frequency of appointments for the study duration, $\mathbf{N}=46$

\begin{tabular}{llll}
\hline Variable & Attribute & OR & IB \\
\hline Met appointments & Mean (SD) & $5.6(0.7)$ & $3.8(2.6)$ \\
& Median & 6 & 3 \\
& Range & $4-6$ & $1-9$ \\
Scheduled appointments & Mean (SD) & $6(0)$ & $5.1(3.1)$ \\
& Median & 6 & 5 \\
& Range & - & $1-10$ \\
\hline
\end{tabular}

the two groups or in the proportion reporting clinical distress (score greater than seven) either at baseline $(\mathrm{p}=.385)$ or three months $(\mathrm{p}=.221)$.

\section{Satisfaction with services}

As shown in Table 8, caregivers in the OR group reported greater satisfaction with services and statistically significant differences were found in all domains apart from the registration process, comfort of the waiting area and being treated with respect.

\section{Discussion and conclusions}

The objectives of the study were to compare the impact of the outreach (OR) and the institutionally based (IB) programs in terms of their impact on the children's functioning, the strain on their caregivers, compliance with scheduled appointments and the overall satisfaction with the services received. It should be noted that the "entire package", which encompassed the location (community or institutional based), the increased training and experience of the OR personnel, the structure of the therapy sessions and the provision of refreshments during the OR sessions were compared. It was not possible, using this research design, to isolate which components of the programmes resulted in the differences seen. The results of the study indicate that in several respects the OR programme was superior to the IB programme. The sample appeared to be representative of children with $\mathrm{CP}$ in that the majority had spastic type CP $(80 \%)$ which is the most common variant of $\mathrm{CP}$ as reportedly accounts for $80-83 \%$ of cases [11,35-37]. The spread across the different GMFCS levels was similar to a large scale study in Canada, which reported $42 \%$ of the children were severely affected (Levels IV and V) compared to $44 \%$ in this study [31]. The predominance of males in the sample has also been reported in other samples of children with CP $[6,38,39]$. It would therefor appear that the children in this study were representative of most samples of children with CP.

A problem with quasi-experimental studies is that there may be confounding variables that may bias the 
Table 4 Change in GMFM 66 scores over three months, $n=46$

\begin{tabular}{llllllll}
\hline & IB & OR & Total & Statistic & p-value & Confidence-95\% & Confidence + 95\% \\
\hline Baseline, Mean (SD) & $42.9(8.1)$ & $39.7(14.4)$ & $41.5(11.2)$ & $\mathrm{t}=2.04$ & 0.047 & -5.20 & -0.04 \\
Three months, Mean (SD) & $43.5(9.0)$ & $44.9(19.8)$ & $44.1(14.5)$ & $\mathrm{df}=45$ & & & \\
\hline
\end{tabular}

results of the study. In this case, there were no differences found between the participants in the OR group and the IB group in terms of demography or nature of their impairment. The differences that were noted, that the OR children were older and more were severely affected (although not statistically so), would have introduced bias into a randomised trial. However, in this pragmatic trial it was an indication of the strength of the OR intervention in that older, more severely affected children were still being brought in for treatment. It has been reported that older and more severely affected children might respond less to interventions, [12]. It was thus necessary to control for these factors by doing regression analysis. Children in the OR group showed greater improvement and several factors can account for this difference. Firstly, some of the rehabilitation workers in the OR group are based in a specialist unit and have developed skills in child treatment whereas the IB rehabilitation professionals are responsible for treatment across a wider spectrum of conditions and ages. Secondly, the lower child to therapist ratio in the OR group ensures ample time for treatment and demonstration of techniques to caregivers. Thirdly, continuity of care in the OR group,and the inherent good therapist-child relationship may have led to increase in-treatment adherence and this may have enhanced treatment efficacy [40].

The situation in Zimbabwe is typical of a resource constrained country in that children with severe CP are not necessarily catered for within institutions or special schools. The response to therapy might be different in children who have had on-going intensive rehabilitation within specialised centres. In addition, parents who have had access to sophisticated services may not demonstrate the same degree of satisfaction with the type of service provided. The results of the study may therefore only be of relevance to low and middle income countries.

As the children in the community based group were older and higher proportions were in GMFCS Levels IV

Table 5 Predictors of the change in GMFM-66 scores over three months, $n=46$

\begin{tabular}{lllll}
\hline & $\begin{array}{l}\text { Amount of } \\
\text { change }-\mathbf{~ b}\end{array}$ & $\begin{array}{l}\text { Standard } \\
\text { error of } \mathbf{~}\end{array}$ & $\mathbf{t ( 4 1 )}$ & p-value \\
\hline Intercept & -0.39 & 0.61 & -0.6 & 0.526 \\
OR group & 2.49 & 0.75 & 3.3 & 0.002 \\
Minimal severity & 1.96 & 0.67 & 2.9 & 0.005 \\
Age (months) & -0.02 & 0.01 & -2.3 & 0.029 \\
\hline
\end{tabular}

and $\mathrm{V}$, their caregivers might be expected to report greater strain. This was not the case, which might indicate that the outreach based intervention mitigated the impact of severity and chronicity of care to a certain extent. This hypothesis however, needs to be empirically tested. Alternatively, it may be that parents of younger children are in earlier phases of 'grief' in response to having a child with a disability which may dissipate over time to some extent [41]. It is clear that the care-givers are in need of additional support, particularly financial and emotional as there are no disability grants in Zimbabwe.

Caregivers in the OR group seemed to be more satisfied with services and were more compliant as compared to recipients of IB services. It is essential to evaluate patient satisfaction with services delivery as satisfaction is related to treatment compliance and outcomes [33,42]. Services in the OR group were provided every fortnight and this could have enhanced satisfaction and compliance with services. Furthermore, consistent booking schedules have been demonstrated to affect the levels of compliance and satisfaction with services [43-45]. Additionally, provision of services within the recipients' communities, a more natural environment, negates the need for transportation costs and adapted transportation (which may not be available in low resourced settings). It also results in an increased amount of social support. All of which have been identified cited as enhancers to satisfaction and compliance [46-50].

Table 6 Responses to the caregiver strain index $(n=46)$

\begin{tabular}{llllllll}
\hline Number reporting problems & \multicolumn{3}{c}{ Baseline } & & \multicolumn{3}{c}{ At three months } \\
\cline { 2 - 3 } & OR & IB & Total & OR & IB & Total \\
& $\mathbf{n}$ & $\mathbf{n}$ & $\mathbf{n}(\%)$ & $\mathbf{n}$ & $\mathbf{n}$ & $\mathbf{n}(\%)$ \\
\hline Sleep & 3 & 9 & $12(26)$ & 2 & 9 & $11(24)$ \\
Inconvenient & 8 & 16 & $24(52)$ & 10 & 15 & $25(54)$ \\
Physical strain & 10 & 19 & $29(63)$ & 10 & 18 & $28(61)$ \\
Confining & 12 & 13 & $25(54)$ & 9 & 13 & $22(48)$ \\
Family adjustments & 10 & 16 & $26(57)$ & 7 & 14 & $21(46)$ \\
Personal plans & 11 & 19 & $30(65)$ & 11 & 21 & $32(70)$ \\
Emotional adjustments & 7 & 16 & $23(50)$ & 7 & 16 & $23(50)$ \\
Upsetting behaviour & 8 & 7 & $15(33)$ & 6 & 5 & $11(24)$ \\
Has changed & 6 & 6 & $12(26)$ & 7 & 5 & $12(26)$ \\
Work adjustments & 11 & 15 & $26(57)$ & 11 & 13 & $24(52)$ \\
Financial strain & 14 & 15 & $29(63)$ & 17 & 17 & $34(74)$ \\
Overwhelmed & 14 & 22 & $36(78)$ & 16 & 24 & $40(87)$ \\
\hline
\end{tabular}


Table 7 CSI scores comparison at baseline and at three months, $(n=46)$

\begin{tabular}{|c|c|c|c|c|c|c|c|c|c|c|}
\hline & \multicolumn{2}{|c|}{ At baseline } & \multirow[b]{2}{*}{ Total } & \multirow[b]{2}{*}{ Statistic } & \multirow[b]{2}{*}{$p$-value } & \multicolumn{3}{|c|}{ At three months } & \multirow[b]{2}{*}{ Statistic } & \multirow[b]{2}{*}{ p-value } \\
\hline & OR & IB & & & & OR & IB & Total & & \\
\hline \multirow[t]{3}{*}{ Median } & 5.5 & 7 & 6.5 & $U=204$ & 0.219 & 6 & 7 & 7.0 & $U=220$ & 0.381 \\
\hline & & & & $Z=1.230$ & & & & & $Z=0.87$ & \\
\hline & $n$ & $n$ & n (\%) & & & $n$ & $n$ & n (\%) & & \\
\hline Normal (0-6) & 12 & 11 & $23(50)$ & $x^{2}=.796$ & 0.372 & 11 & 11 & $22(48)$ & $x^{2}=.31$ & 0.578 \\
\hline Clinical distress (7-12) & 8 & 15 & $23(50)$ & & & 9 & 15 & $24(52)$ & & \\
\hline
\end{tabular}

Lack of knowledge of the child's impairment can lead to non-compliance [51]. As caregivers in the OR group would have attended $\mathrm{CP}$ workshops prior to joining the outreach group, it was expected that they would have been more knowledgeable about $\mathrm{CP}$. This might have enhanced compliance and satisfaction with the explanations given by therapists on $\mathrm{CP}$ and its treatment. This hypothesis was not tested however and a weakness of the study was that the amount of information that the caregivers had regarding CP was not compared between the groups.

The IB group had a higher patient to therapist ratio; this inherently leads to time pressure during treatment sessions. Time pressure may lead to decreased intreatment adherence, less satisfaction with explanations and therapy given. This may have accounted for the lower compliance and satisfaction in the IB group. The nature of the patient/practitioner relationship also affects the extent of compliance and satisfaction [51]. Further, the absence of continuity of care in the IB group, might also have accounted for lower rate of compliance and satisfaction.

Research on the effect of treatment frequency has yielded inconclusive evidence [12,40,43]. However, a study by Christiansen \& Lange, [43] suggests that intermittent frequency is equally efficacious when compared

Table 8 Responses to the satisfaction with services (Medrisk) questionnaire $(n=46)$

\begin{tabular}{|c|c|c|c|c|c|c|c|c|}
\hline Satisfaction domain & Group & $\begin{array}{l}\text { Strongly } \\
\text { disagree } \mathrm{n}\end{array}$ & $\begin{array}{l}\text { Disagree } \\
\mathbf{n}\end{array}$ & $\begin{array}{l}\text { Neutral } \\
\mathrm{n}\end{array}$ & $\begin{array}{l}\text { Agree } \\
\mathrm{n}\end{array}$ & $\begin{array}{l}\text { Strongly agree } \\
\mathbf{n}\end{array}$ & $\mathrm{Z}$ adj & $p$ value \\
\hline \multirow[t]{2}{*}{ Registration process } & OR & 0 & 0 & 1 & 7 & 12 & 1.4 & 0.221 \\
\hline & $\mathrm{IB}$ & 0 & 0 & 2 & 14 & 10 & & \\
\hline Comfort of waiting & OR & 1 & 0 & 5 & 8 & 6 & 1.1 & 0.317 \\
\hline Area & IB & 0 & 1 & 10 & 11 & 4 & & \\
\hline Time therapist spends & OR & 1 & 1 & 2 & 4 & 12 & 3.1 & 0.002 \\
\hline with child & IB & 0 & 4 & 10 & 10 & 2 & & \\
\hline Amount of explanations & OR & 0 & 0 & 1 & 4 & 15 & 2.9 & 0.006 \\
\hline given by therapist & $\mathrm{IB}$ & 0 & 5 & 4 & 8 & 9 & & \\
\hline Being treated with & OR & 0 & 1 & 1 & 5 & 13 & 1.1 & 0.327 \\
\hline respect & $\mathrm{IB}$ & 0 & 1 & 2 & 11 & 12 & & \\
\hline Having concerns & OR & 0 & 0 & 0 & 4 & 16 & 3.6 & 0.001 \\
\hline listened to & $\mathrm{IB}$ & 0 & 1 & 10 & 7 & 8 & & \\
\hline Having all questions & OR & 0 & 0 & 2 & 3 & 15 & 2.9 & 0.006 \\
\hline answered & IB & 0 & 2 & 7 & 9 & 8 & & \\
\hline Being given future & OR & 0 & 0 & 0 & 5 & 15 & 3.8 & .001 \\
\hline advice & $\mathrm{IB}$ & 1 & 5 & 5 & 9 & 6 & & \\
\hline $\begin{array}{l}\text { Receiving instructions on } \\
\text { home exercise }\end{array}$ & OR & 0 & 1 & 2 & 2 & 15 & 2.3 & 0.035 \\
\hline program & $\mathrm{IB}$ & 2 & 3 & 4 & 6 & 11 & & \\
\hline \multirow[t]{2}{*}{ Overall satisfaction } & OR & 0 & 1 & 1 & 5 & 13 & 3 & 0.004 \\
\hline & $\mathrm{IB}$ & 4 & 3 & 6 & 6 & 7 & & \\
\hline If they will return for & OR & 0 & 0 & 2 & 4 & 14 & 2.3 & 0.037 \\
\hline future services & $\mathrm{IB}$ & 0 & 1 & 8 & 7 & 10 & & \\
\hline
\end{tabular}


to continuous dosage. Therefore, evidence from our findings suggests that a two week gap may be tolerable for caregivers and may result in equal gains in functional outcome.

Results from this study need to be interpreted with caution as children and caregivers had had interventions for varying lengths of time and changes in the outcome measures might have taken place prior to the study. Secondly, methodological weakness of the study design and the lack of randomisation and blinding of the assessor may limit the generalizability of our findings. Thirdly, there was a difference in expertise and clinical experience for therapists in the comparison groups with those in the OR arm more experienced and this could have introduced bias.

In conclusion, long term caregiving leads to strain in caregivers and there is a need to design individualized interventions to alleviate the burden on caregivers as it may ultimately affect the child's functional prognosis and health outcomes. The study was a pragmatic, quasiexperimental study, which by its nature cannot lead to causal inference. However findings from this study suggest that the provision of care within a community setting as part of a well-structured OR programme may be preferable. It was associated with a greater improvement in functioning, greater satisfaction with services and better compliance. In addition, care-givers continued to bring in older children for therapy, which was encouraging. It is therefore suggested that may be the preferred method of service delivery. Further research is needed however, to cost the methods of service delivery in order to determine the cost of transferring the management of children with $\mathrm{CP}$ from institutions to the community.

\section{Abbreviations}

CBR: Community based rehabilitation; CP: Cerebral palsy; CRU: Children rehabilitation unit; CSI: Caregiver strain index; GMFCS: Gross motor function classification system; GMFM: Gross motor function measurement; GMFM-66: Gross motor function measure -66; HCH: Harare central hospital; HRQoL: Health- related quality of life; IB: Institution-based; MOHCWZ: Ministry of health and child welfare Zimbabwe; MRPS: Medrisk instrument for measuring patient satisfaction with physical therapy care; OR: Outreach-based; WHO: World Health Organization.

\section{Competing interests}

The authors declare that they have no competing interests.

\section{Authors' contributions}

Both JD and JJ contributed to the conceptualisation of the study, the analysis and write-up of the paper. JD was responsible for the data collection. Both authors read and approved the final manuscript.

\section{Acknowledgements}

The University of Zimbabwe for the funding which allowed the study to take place. Appreciation is expressed to the caregivers and children with CP who participated in this study. We applaud your commitment and cooperation throughout the duration of this study. Kapneck Trust, Save the Children Fund and Dr Greg Powell for providing support to the Outreach programme.

\section{Author details}

${ }^{1}$ Research Fellow at University of Cape Town, Lecturer Department of Rehabilitation, College of Health Sciences, University of Zimbabwe, PO Box
AV 178, Avondale, Harare, Zimbabwe. 'Division of Physiotherapy, Department of Health and Rehabilitation Sciences, Faculty of Health Sciences, University of Cape Town, Anzio Road, Observatory, Cape Town, South Africa.

Received: 25 June 2014 Accepted: 25 November 2014

Published online: 05 December 2014

\section{References}

1. Gagliardi C, Maghini C, Germiniasi C, Stefanoni G, Molteni F, Burt DM, Turconi AC: The effect of frequency of cerebral palsy treatment: a matched-pair pilot study. Pediatr Neurol 2008, 39:335-340.

2. Berker AN, Yalçin MS: Cerebral palsy: orthopedic aspects and rehabilitation. Pediatr Clin North Am 2008, 55:1209-1225. ix.

3. Martin B, Murray G, Peter R, Alan L, Nigel P: Proposed definition and classification of cerebral palsy, April 2005.pdf. Dev Med Child Neurol 2005, 47:571-576

4. Clark S, Hankins G: Temporal and demographic trends in cerebral palsy Fact and fiction. Am J Obstet Gynecol 2003, 188:628-633.

5. Finkenflugel H, Maannen W, Schut W, Vermeer A, Jelsma J, Moyo A: Appreciation of community based rehabilitation by caregivers of children with a disability. Disabil Rehabil 1996, 18:255-260.

6. Moster D, Wilcox AJ, Vollset SE, Markestad T, Lie RT: Cerebral palsy among term and postterm births. JAMA 2010, 304:976-982.

7. Sharan D, Ajeesh PS, Rameshkumar R, Manjula M: Musculoskeletal disorders in caregivers of children with cerebral palsy following a multilevel surgery. Work A J Prev Assess Rehabil 2012, 41 Suppl 1:1891-1895.

8. Jones MW, Morgan E, Shelton JE, Thorogood C: Cerebral palsy: introduction and diagnosis (part I). J Pediatr Health Care 2007, 21:146-152.

9. Hamzat TK, Mordi EL: Impact of Caring for Children with Cerebral Palsy on the General Health of Their Caregivers in an African Community, Volume 30. 2007:191-194.

10. Davis E, Shelly A, Waters E, Boyd R, Cook K, Davern M: The impact of caring for a child with cerebral palsy: quality of life for mothers and fathers. Childcare, Heal Dev 2009, 36:63-73.

11. Aisen ML, Kerkovich D, Mast J, Mulroy S, Wren TA, Kay RM, Rethlefsen SA Cerebral palsy: clinical care and neurological rehabilitation. Lancet Neurol 2011, 10:844-852.

12. Law MC, Darrah J, Pollock N, Wilson B, Russell DJ, Walter SD, Rosenbaum P, Galuppi B: Focus on function: a cluster, randomized controlled trial comparing child- versus context-focused intervention for young children with cerebral palsy. Dev Med Child Neurol 2011, 53:621-629.

13. National programme for rehabilitation of persons with disabilities - A blend of CBR and IBR [http://english.aifo.it/disability/apdrj/frimeet202/national.doc]

14. Olaogun MOB, Nyante GG, Ajediran A: Overcoming the Barriers for Participation by the Disabled: An appraisal and global view of community-based rehabilitation in community development. Community Health (Bristol) 2009, 1(No.1 June):24-29.

15. Community-based rehabilitation: CBR Guidelines [http://www.who.int/ disabilities/cbr/guidelines/en/]

16. Mitchell REG: The research base of community-based rehabilitation. Disabil Rehabil 1999, 21:459-468.

17. Myezwa H, M'kumbuzi V: Participation in community based rehabilitation programmes in Zimbabwe: where are we? Asia Pacific Disabil Rehabil J 2003, 14:18-29.

18. Community-Based Rehabilitation as we have experienced it ...voices of persons with disabilities [http//whqlibdoc.who.int/publications/9241590432.pdf]

19. Velema JP, Cornielje $\mathrm{H}$ : Reflect before you act: providing structure to the evaluation of rehabilitation programmes. Disabil Rehabil 2003, 25:1252-1264.

20. Sharma M: Viable methods for evaluation of community-based rehabilitation programmes. Disabil Rehabil 2004, 26:326-334.

21. Cornielje H, Velema JP, Finkenflu H: Community based rehabilitation programmes: monitoring and evaluation in order to measure results. Lepr Rev 2008, 79:36-49.

22. A comparison of hospital-based and community based models of cerebral palsy rehabilitation. [https://open.uct.ac.za/browse?value=Dambi\% $2 \mathrm{C}+$ Jermaine+Matewu\&type $=$ author]

23. The national health strategy for Zimbabwe (2009 - 2013) [http://apps.who. int/medicinedocs/en/d/Js17996en/]

24. Debuse $\mathrm{D}$, Brace $\mathrm{H}$ : Outcome measures of activity for children with cerebral palsy: a systematic review. Pediatr Phys Ther 2011, 23:221-231. 
25. Trahan J, Malouin F: Intermittent intensive physiotherapy in children with cerebral palsy: a pilot study. Dev Med Child Neurol 2002, 44:233-239.

26. Tsorlakis N, Evaggelinou C, Grouios G, Tsorbatzoudis C: Effect of intensive neurodevelopmental treatment in gross motor function of children with cerebral palsy. Dev Med Child Neurol 2004, 46:740-745.

27. Chen M-L, Hu L-C: The generalizability of Caregiver Strain Index in family caregivers of cancer patients. Int J Nurs Stud 2002, 39:823-829.

28. Narekuli A, Raja K, Kumaran S: Impact of physical therapy on burden of caregivers of individuals with functional disability. Disabilty, CBR Ind Dev 2011, 22:108-119.

29. Palisano R, Rosenbaum P, Walter S, Russell D, Wood E, Galuppi B: Development and reliability of a system to classify gross motor function in children with cerebral palsy. Dev Med Child Neurol 1997, 39:214-223.

30. Mccarthy ML, Silberstein CE, Atkins EA, Harryman SE, Sponseller PD, Hadley-Miller NA: Comparing reliability and validity of pediatric instruments for measuring health and well-being of children with spastic cerebral palsy. Dev Med Child Neurol 2002, 44:468-476.

31. Gorter JW, Rosenbaum PL, Hanna SE, Palisano RJ, Bartlett DJ, Russell DJ, Wood E, Walter SD, Raina P, Galuppi BE: Limb distribution, motor impairment, and functional classification of cerebral palsy. Dev Med Child Neurol 2004, 46:461-467.

32. Robinson B: Validation of a Caregiver Strain Index. J Gerontol 1983, 38:344-348.

33. Harding KE, Taylor NF: Highly satisfied or eager to please? Assessing satisfaction among allied health outpatients. Int I Ther Rehabil 2010, 17:353-359.

34. Raina P, Donnell MO, Rosenbaum P, Brehaut J, Stephen D, Russell D, Swinton M, Zhu B, Wood E, Walter SD: The Health and Well-Being of Caregivers of Children With Cerebral Palsy The online version of this article, along with updated information and services, is located on the World Wide Web at: The Health and Well-Being of Caregivers of Children With Cereb. 2012.

35. Becher JG: Pediatric Rehabilitation in Children with Cerebral Palsy: General Management, Classification of Motor Disorders. Am Acad Orthotists Prosthetists 2002, 14:143-149.

36. O'Shea TM: Diagnosis, Treatment, and Prevention of Cerebral Palsy in Near- Term/Term Infants. Clin Obstet Gynecol J 2008, 51:816-828.

37. Health-related Quality of Life of Nigerian Children with Cerebral Palsy., 22:95-104

38. Eker L, Tüzün EH: An evaluation of quality of life of mothers of children with cerebral palsy. Disabil Rehabil 2004, 26:1354-1359.

39. Cheshire A, Barlow JH, Powell LA: The psychosocial well-being of parents of children with cerebral palsy: a comparison study. Disabil Rehabil 2010, 32:1673-1677

40. Ustad $T$, Sorsdahl $A B$, Ljungren AE: Effects of intensive physiotherapy in infants newly diagnosed with cerebral palsy. Pediatr Phys Ther 2009, 21:140-148. discussion 149.

41. Morgan P: BMC Paediatrics Reviewer's Report -The Impact of Hospital-Based and Community Based Models of Cerebral Palsy Rehabilitation: A Quasi-Experimental Study; 2014

42. Client Satisfaction Evaluations [http://www.emcdda.europa.eu/attachements. cfm/att_5868_EN_6_client_satisfaction_evaluations.pdf]

43. Christiansen AS, Lange C: Intermittent versus continuous physiotherapy in children with cerebral palsy. Dev Med Child Neurol 2008, 50:290-293.

44. Hills $R$, Kitchen S: Development of a model of patient satisfaction with physiotherapy. Physiother Theory Pract 2007, 23:255-272.

45. Mendonça K, Guerra R: Development and validation of an instrument for measuring patient satisfaction with physical therapy. Rev bras fisioter, São Carlos 2007, 11:369-376.

46. Ogunlesi T, Chb MB, Ogundeyi M, Olowu A, Bs MB: Socio-clinical issues in cerebral palsy in Sagamu, Nigeria. SA J Child Heal 2008, 2:120-123.

47. Vermeire E, Hearnshaw H, Royen PV, Denekens J: Patient adherence to treatment: three decades of research. A comprehensive review. J Clin Pharm Ther 2001, 26:331-342.

48. Middleton A: Chronic low back pain: patient compliance with physiotherapy advice and exercise, perceived barriers and motivation. Phys Ther Rev 2004, 9:153-160.

49. Murphy KM, Rasmussen L, Hervey-jumper SL, Justice D, Nelson VS, Yang L: An assessment of the compliance and utility of a home exercise DVD for caregivers of children and adolescents with brachial plexus palsy: a pilot study. Am Acad Phys Med Rehabil 2012, 4:190-197.
50. Alexandre NMC, Nordin M, Hiebert R, Campello M: Predictors of compliance with short-term treatment among patients with back pain. Rev Panam salud pública/Pan Am J public Heal 2002, 12:86-94.

51. Escolar-reina P, Medina-mirapeix F, Gascón-cánovas JJ, Montilla-herrador J, Jimeno-serrano FJ, Sousa SLDO, Baño-aledo ME, Lomas-vega R: How do care-provider and home exercise program characteristics affect patient adherence in chronic neck and back pain : a qualitative study. BMC Health Serv Res 2010, 10:1-8.

doi:10.1186/s12887-014-0301-8

Cite this article as: Dambi and Jelsma: The impact of hospital-based and community based models of cerebral palsy rehabilitation:

a quasi-experimental study. BMC Pediatrics 2014 14:301.

\section{Submit your next manuscript to BioMed Central and take full advantage of:}

- Convenient online submission

- Thorough peer review

- No space constraints or color figure charges

- Immediate publication on acceptance

- Inclusion in PubMed, CAS, Scopus and Google Scholar

- Research which is freely available for redistribution 